\title{
AMAR
}

AMAR (Andalas Management Review)

Vol. 3, No. 1 (2019) 115-132

The Management Institute, Faculty of Economics, Universitas Andalas

ISSN (Print) 2476-9282 | ISSN (Online) 2548-155X

\section{ANALISIS PENGARUH CITRA MEREK,PERSEPSI HARGA, SIKAP MEREK, LOKASI dan WORD OF MOUTH TERHADAP NIAT MENONTON di CINEMA XXI KOTA PADANG}

\author{
Ullya Rahmi Aswinª, Danny Hidayat ${ }^{\mathrm{b}}$ \\ aProgram Studi Manajemen Universitas Putra Indonesia YPTK, aswinullyarahmi@gmail.com \\ bJurusan Manajemen Universitas Andalas, dannyhidayat@eb.unand.ac.id
}

\begin{abstract}
This study aims to analyze the influence of Brand Image, Price Perception, Brand Attitudes, Location and Word of Mouth to Purchase Intention at Cinema XXI Padang City. The sample of this research is the first time viewers in Cinema XXI in Padang City as many as 208 respondents. The research data processing is done by using SEM (Structural Equation Modeling) method, with the type of Structural Equation Modeling (SEM) used by Smart Pls. The results showed that Brand Image, Price Perception, Brand Attitudes, Location and Word of Mouth positively influence the Purchase Intention

Key Words: Brand Image, Price Perception, Brand Attitude, Location, Word of Mouth, Purchase Intention
\end{abstract}

\section{PENDAHULUAN}

Pada era saat ini dapat kita lihat dalam kehidupan sehari - hari terutama di kota- kota besar seperti Kota Padang banyak orang selalu sibuk dengan pekerjaan dan rutinitas seharihari. Hal ini menyebabkan banyak orang pasti membutuhkan suatu sarana untuk melepas ketegangan akibat rutinitas yang mereka lakukan. Karena jika bekerja terlalu lama maka mereka akan jenuh dengan pekerjaannya dan akan menyebabkan stres. Stres adalah penyebab utama kecacatan permanen dan gangguan kesehatan dalam jangka panjang. Dan stres menyebar lebih luas dari pada penyakit kronis seperti stroke, serangan jantung, kanker, dan gangguan pada punggung. Para peneliti percaya stres paling sering dialami di termpat kerja, akibat guncangan ekonomi berkepanjangan (Tahapary Grace 2015).

Untuk menghindari hal tersebut, ketika sudah merasa jenuh, dapat diantisipasi dengan melakukan hiburan menonton film. Menonton film dapat dilakukan di dalam rumah 
dengan menonton acara di televisi, VCD, DVD.Menonton film pun dapat dilakukan di luar yaitu di bioskop. Bioskop berasal dari kata BOSCOOP (bahasa Belanda yang juga berasal dari Bahasa Yunani) yang artinya Gambar Hidup. Bioskop sendiri adalah tempat untuk menonton pertunjukan film dengan menggunakan layar lebar, gambar film dengan menggunakan proyektor dan dilengkapi sound system yang bagus. Dalam hal ini, menonton film di bioskop juga memiliki kekurangan yaitu: besarnya biaya yang harus dikeluarkan (biaya tiket film, biaya transportasi, biaya konsumsi). Tetapi semua biaya itu akan terbayar dengan adanya rasa puas kita setelah menonton bioskop yang bisa ditimbulkan dari menonton rame-rame bersama teman, tempat yang nyaman, suara yang canggih, layar yang lebar, dan menonton film terbaru.

Bioskop di Indonesia ini berkembang seiring dengan perkembangan zaman. Kategori dari bioskop di Indonesia adalah bioskop Cinema 21, XXI dan the premiere. Mereka dibuat untuk ditargetkan sesuai dengan pangsa pasar yang berbeda mulai dari yang menengah kebawah sampai menengah keatas.

Kondisi yang sama tidak terlihat di Padang. Padang tidak mengenal Cinema XXI apalagi Mega Blitz. Beberapa bioskop yang tersisa di Padang tetapi bertahan dengan bioskop model "tempo doeloe" dengan fasilitas yang kurang memadai baik dari segi fasilitas, kualitas maupun pelayanan.

Informasi mengenai hadirnya Cinema XXI di Plaza Andalas Padang beredar di dunia maya dan menjadi bahan perbincangan di tengah masyarakat, terutama pecinta film dan bioskop. Kehadiran XXI di Kota Padang akan menjawab kebutuhan masyarakat yang selama ini merindukan hadirnya sebuah bioskop yang layak. Mengingat selama ini bioskop-bioskop yang ada di Kota Padang bisa dibilang tidak layak dan sering dikaitkan dengan prilaku negatif yang dilakukan oleh oknum penonton terutama muda-mudi.

Bioskop Cinema XXI sudah tersimpan dalam benak konsumen suatu merek yang sudah lama dikenal oleh masyarakat Kota Padang yang akhirnya hadir di Kota Padang berlokasi di Plaza Andalas. Plaza yang berada di Jl. Pemuda tersebut bisa diakses dengan menggunakan kendaraan umum angkutan kota yang menjadi magnet baru bagi warga untuk berlibur sambil menonton film terbaru yang lagi booming produksi dalam negeri maupun mancanegara. bioskop yang telah lama ditunggu-tunggu warga Padang tersebut tak hanya update dalam film tapi juga memiliki ruangan yang memiliki infrastruktur menarik dengan warna keemasan. Bioskop Cinema XXI memang menjadi fenomena baru bagi penggemar film dan bioskop dewasa ini. Cinema XXI mampu mengambil celah dalam pergeseran hiburan yang disukai oleh masyarakat saat ini yakni mall atau pusat perbelanjaan, oleh sebab itu 
pengusaha bioskop menjadikan pusat perbelanjaan dan bioskop sebagai satu paket hiburan bagi masyarakat.

Bioskop Cinema XXI menjadi trade mark bioskop era sekarang, dan metode tersebut ternyata cukup "ampuh" untuk mengembalikan niat menonton masyarakat yang mulai meninggalkan bioskop sejak awal tahun 2000-an. Cinema XXI mampu bersaing dengan kecanggihan teknologi lain yang membuat film bisa saja disaksikan oleh masyarakat di rumah ala home theatre. Tetapi di Kota Padang hanya XXI saja dikarenakan untuk The Premiere, masyarakat Kota Padang belum butuh karena harga yang dipatok mulai dari tiket, makanan dan harga - harga penunjang lain sangat mahal.

Pertambahan bioskop dari waktu ke waktu semakin bertambah banyak dapat kita lihat pada grafik berikut ini:

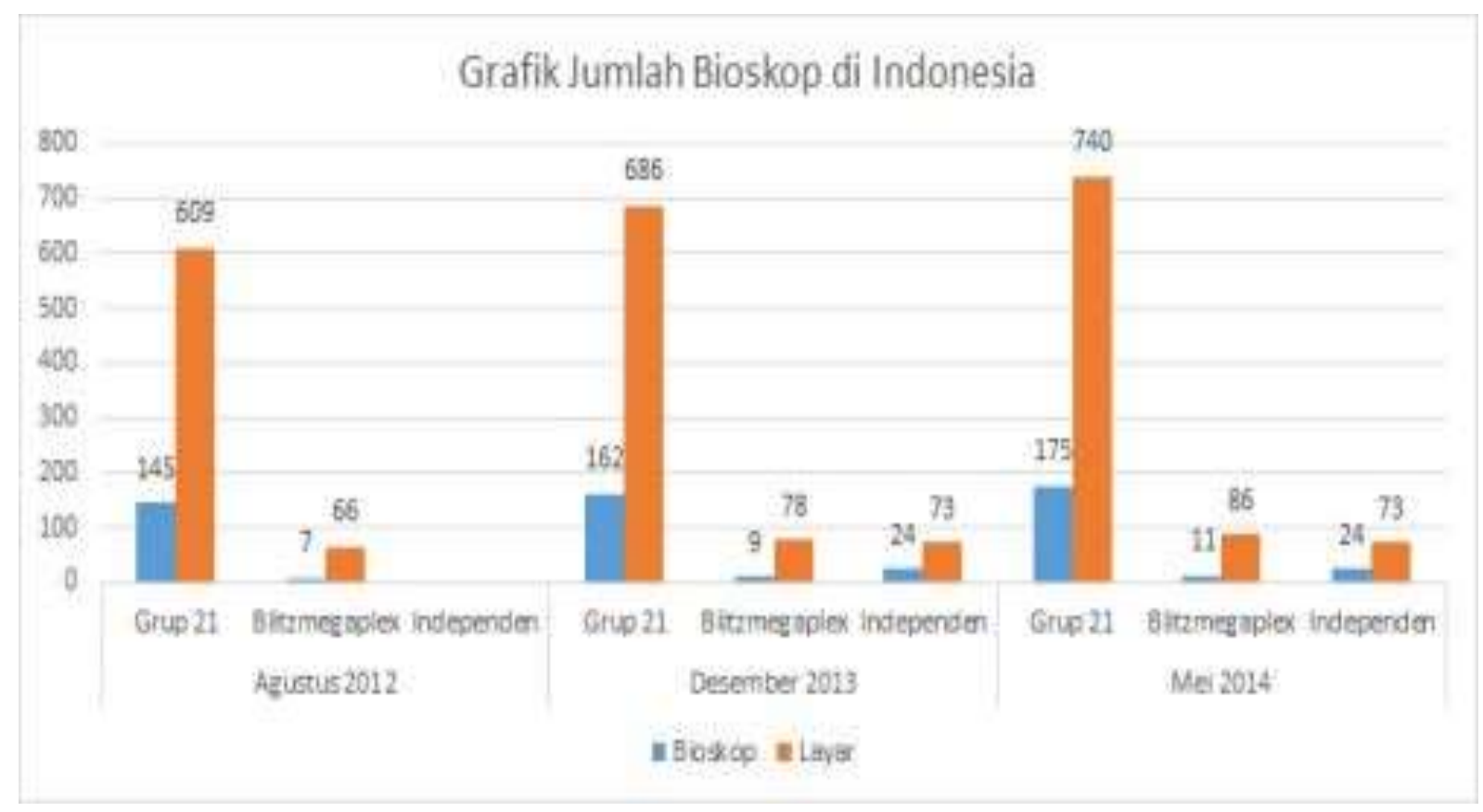

Gambar 1 : Jumlah bioskop di Indonesia (2013-2014).

. Jika kita melihat grafik diatas, dalam waktu 1,5 tahun, Pertambahan bioskop di jaringan grup 21 Dari bulan Agustus 2012 - Desember 2013 sekitar 10 persen. Pada Agustus 2012, jumlah bioskop pada Grup 21 berjumlah 145 bioskop dengan 609 layar, kemudian sampai dengan Desember 2013, Grup 21 menambah 17 bioskop sehingga berjumlah 162 bioskop dengan 686 layar. Pada rentang waktu yang sama, kondisi serupa juga terjadi pada jaringan Grup Blitzmegaplex yang mengalami pertambahan pada kisaran 22 persen. Pada Agustus 2012, Grup Blitzmegaplex memiliki tujuh bioskop dengan 66 laya, kemudian pada Desember 2013, Gruo Blitzmegaplex menambah dua bioskop sehingga berjumlah 9 bioskop 
dengan 78 layar. Peningkatan jumlah bioskop meningkat hingga sekarang. Untuk Kota Padang Bioskop Cinema XXI telah bertambah pada bulan November 2016 di Plaza Andalas dan pada Bulan Mei 2017 lalu di Transmart Project Padang.

Kehadiran Bioskop Cinema XXI pada Bulan November tahun 2016 menjadi booming warga Kota Padang • pada tahun pertama pembukaan Bioskop Cinema XXI di Plaza Andalas Kota Padang menjaring konsumen mencapai 4000 penonton dan meningkat dari tiap bulannya.

Tabel 1

Jumlah Kunjungan Penonton di Cinema XXI Kota Padang

\begin{tabular}{cc}
\hline Bulan & Rata-rata jumlah kunjungan \\
\cline { 2 - 2 } & Per bulan \\
\hline November & 481.328 \\
\hline Desember & 530.009 \\
\hline Januari & 674.123
\end{tabular}

Sumber: Data primer diolah peneliti ke Cinema XXI kota Padang (2017).

Dari tabel di atas membuktikan bahwa adanya peningkatan kunjungan penonton ke Cinema XXI dari Bulan November 2016 - Bulan Januari 2017. Perbandingan jumlah kunjungan perbulan penonton hampir mencapai 100\% penonton. Menurut Coorporate Secretary XXI, Catherine Keng (2016) memaparkan data jumlah penonton di bioskop pada tahun 2016. Jumlah penonton Indonesia tahun 2016 naik lebih dari 100\% dibanding periode sebelumnya.

Kebangkitan bioskop di Kota Padang dimulai sejak tahun 2016 seiring membaiknya kondisi perekonomian masyarakat ditambah dengan maraknya industri film Indonesia. Ada beberapa faktor yang membuat jumlah perolehan penonton film Indonesia meningkat. Salah satunya semakin banyaknya film Indonesia yang diproduksi dengan sangat baik. Meski film Indonesia mengalami kenaikan, Bioskop Cinema XXI memberikan seleksi ketat bagi film yang hendak diputar di bioskop. Hal ini juga berarti para produser banyak membuat film yang disukai oleh masyarakat.

Berikut peredaran film yang dikeluarkan oleh Cinema XXI dari tahun 2013-2014.

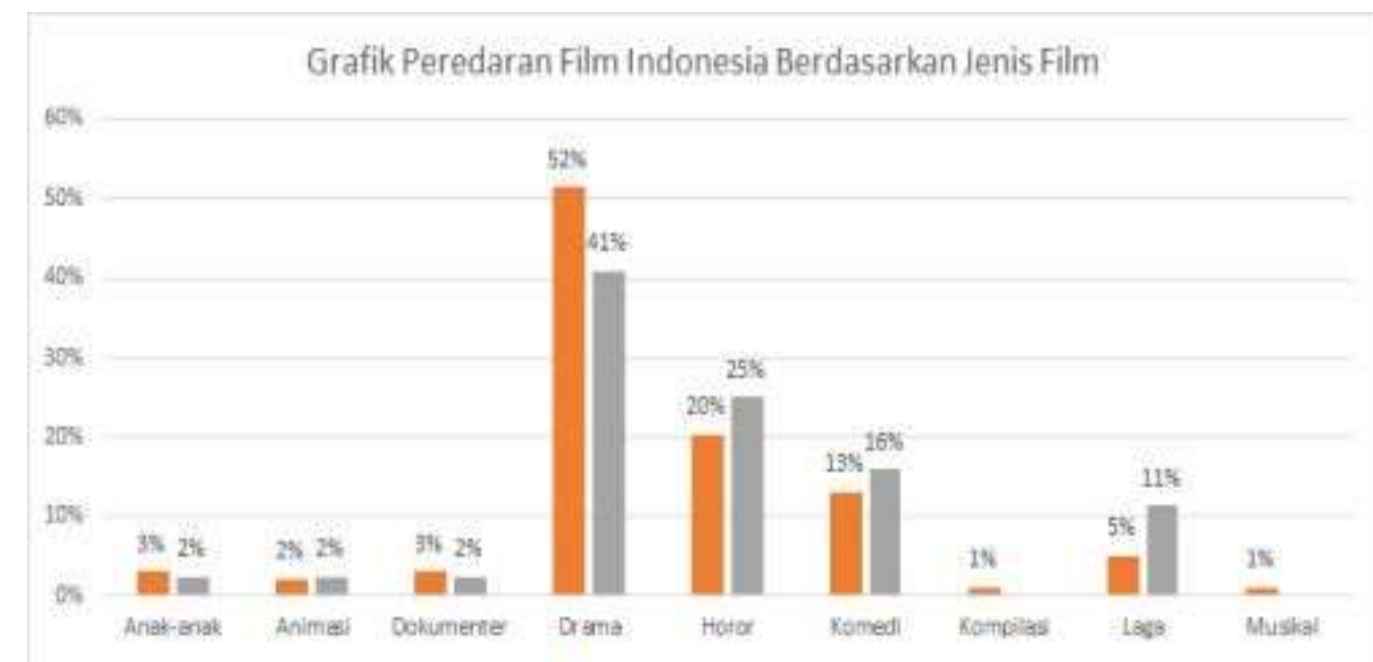


Gambar 2: Peredaran film Indonesia berdasarkan jenis film.

Sepanjang tahun 2013, jenis film yang ditawarkan juga banyak ragamnya. Dari 99 film yang beredar pada tahun 2013, terdapat 3 besar jenis film yang mendominasi peredaran film yaitu Drama, Horor, dan Komedi. Sebagai catatan, film dengan kategori thriller, drama thriller, dimasukan dalam kategori horor dan film dengan kategori drama komedi, horor komedi dimasukan dalam kategori komedi. Apabila dirinci, hasilnya adalah sebagai berikut : Drama menguasai sekitar 52 persen, Horor dengan presentase 20 persen serta Komedi dengan 16 persen dari total film yang beredar. Sisanya, diisi oleh film Laga yang menguasai 5 persen film yang beredar, dan film berkategori anak-anak, animasi, dokumenter, kompilasi, dan musikal yang mengisi 1-3 persen peredaran film.

Selain tempat favorit setiap orang yang menurutnya mall itu adalah tempat nyaman karena bersih, adem, tidak kotor, penuh gemerlap cahaya lampu, Dengan alasan seperti itu, banyak orang yang pergi ke Mall selain belanja dan juga untuk tempat berekreasi dengan keluarga,teman dan kerabat lainnya.

Gaya hidup penduduk Kota Padang sesuai dengan positioning Cinema XXI dimana konsumen butuh tempat yang berbeda, tidak hanya datang untuk menonton film, tetapi Cinema XXI juga bisa dijadikan tempat berkumpul (hangout) atau tempat gaul untuk anak usia muda. Sesuai dengan slogan (tagline) beyond movie, Cinema XXI bertekad membangun gaya hidup baru dalam industri jasa hiburan menonton film di Kota Padang.

Sebelum memutuksan untuk menonton di Cinema XXI, kebanyakan dari calon konsumen akan mencari informasi/input mengenai produk yang dihasilkan atau tempat terlebih dahulu, termasuk dalam penggunaan jasa hiburan menonton di Cinema XXI. Tidak sedikit melalui word of mouth atau lebih dikenal dengan istilah WOM mereka mendapatkan informasi tersebut. Mereka mencari berbagai informasi sesuai dengan kebutuhannya, misalkan saja pergi menonton ke Cinema XXI yang sesuai dengan budget yang mereka miliki, lokasi yang strategis, mengutamakan kenyamanan, fasilitas, dan masih banyak lagi kriteria lainnya yag di inginnkan oleh konsumen. Konsumen akan melakukan pencarian informasi yang aktif melalui word of mouth mengenai hal- hal yang mereka butuhkan. Karena word of mouth yang positif dapat meningkatkan niat beli seseorang. 
Kotler \& Keller (2007) mengemukakan bahwa word of mouth Communication (WOM) atau komunikasi dari mulut ke mulut merupakan proses komunikasi yang berupa pemberian rekomendasi baik secara individu maupun kelompok terhadap suatu produk atau jasa yang bertujuan untuk memberikan informasi secara personal.

Penelitian ini dilakukan untuk menjelaskan pengaruh citra merek, persepsi harga, sikap merek,lokasi dan wom terhadap minat beli pada penonton Cinema XXI di Kota Padang

\subsection{TINJAUAN PUSTAKA}

a. Niat Menonton

Menurut Kuntjara, (2007) niat beli pada dasarnya adalah perilaku pelanggan dimana pelanggan merespon positif terhadap kualitas pelayanan suatu perusahaan dan berniat melakukan kunjungan kembali atau mengkonsumsi kembali produk perusahaan tersebut. Niat membeli adalah suatu tahapan terjadinya keputusan untuk membeli suatu produk. Individu dalam mengambil keputusan untuk membeli suatu barang atau jasa ditentukan oleh dua faktor, yaitu :

1) Faktor luar atau faktor lingkungan yang mempengaruhi individu seperti lingkungan keluarga, kantor, kampus, sekolah, organisasi dan sebagainya.

2) Faktor dalam diri individu, seperti kepribadiannya sebagai calon konsumen.

b. Indikator- indikator niat menonton.

1) Konsumen sungguh- sungguh melakukan pembelian produk

2) Konsumen berusaha membeli produk

3) Konsumen tetap melakukan pembelian produk

4) Konsumen akan melakukan pembelian pada waktu yang akan datang

5) Konsumen serius akan membeli produk

6) Konsumen berpikir bahwa dengan melakukan pembelian merupakan suatu hal baik

c. Citra Merek

Definisi tentang merek dijelaskan oleh Kotler dan Armstrong (2007) dalam bukunya Dasar - Dasar Pemasaran Principles of Marketing. Menurut mereka merek adalah nama, istilah, tanda, simbol, rancangan, atau kombinasi dari semua ini yang dimaksudkan untuk mengenali produk atau jasa dari seseorang atau penjual dan untuk membedakannya dari produk pesaing. Jadi merek mengidentifikasi pembuat atau penjual dari suatu produk. Merek juga merupakan janji penjual untuk menyampaikan kesimpulan sifat, manfaat, dan jasa spesifik secara konsisten kepada 
pembeli. Citra Perusahaan merupakan asosiasi yang berkaitan dengan organisasi dengan atribut dari suatu perusahaan seperti tingkat teknologi, dan gaya kepemimpinan. Semakin baik citra suatu perusahaan maka produk-produk dari perusahaan tersebut akan mudah untuk diterima oleh konsumen.

d. Elemen Citra Merek.

1) Keuntungan dari asosiasi merek.

Konsumen percaya bahwa atribut dan manfaat yang diberikan oleh suatu merek dapat memuaskan kebutuhan dan keinginan konsumen, sehingga menciptakan sikap yang positif terhadap merek. Tujuan akhir dari setiap konsumen adalah mendapatkan kepuasan atas kebutuhan dan keinginan yang ada.

2) Kekuatan dari asosiasi merek

Tergantung pada bagaimana informasi masuk dalam ingatan konsumen dan bagaimana informasi tersebut dikelola oleh data sensoris otak sebagai bagian dari brand image. Konsumen memandang suatu obyek stimuli melalui sensasi- sensasi yang mengalir melalui kelima indra: mata, telinga, hidung, kulit, dan lidah.

3) Keunikan dari asosiasi merek.

Merek harus unik dan menarik, sehingga dapat menimbulkan asosiasi yang kuat di dalam pikiran pelanggan. Merek harus dapat melahirkan keinginan pelanggan mengetahui lebih jauh dimensi merek yang terkandung di dalamnya. Nama perusahaan yang bonafid juga mampu mendukung keunikan asosiasi merek.

\section{a. Sikap Merek}

Sikap merupakan evaluasi, perasaan emosional, dan kecenderungan tindakan yang menguntungkan atau tidak menguntungkan dan bertahan lama dari seseorang terhadap suatu objek atau gagasan (Kotler, 2009). Sikap tersebut juga memiliki fungsifungsi tersendiri.

Sikap adalah kecenderungan, pandangan, pendapat atau pendirian seseorang untuk menilai suatu objek atau persoalan dan bertindak sesuai dengan penilaiannya dengan menyadari perasaan positif dan negatif dalam menghadapi suatu objek (Azwar, 2010). 
Sikap (attitude) ialah pernyataan evaluatif, baik yang menyenangkan maupun tidak menyenangkan terhadap objek, individu, atau peristiwa.

Menurut Tsordia,C. \& Papadimitriou, D. (2015)' Solesvik et al., Linan and Chen, (2006) hal yang perlu diperhatikan dalam attitude towards the behaviour.

1) It is more profitable (sebuah hal yang menguntungkan)

2) It is pleasant (kenyamanan atau kepuasan tersendiri)

3) It is desirable (keinginan)

4) It is attractive (menarik)

5) It has more advantages (memiliki banyak keuntungan)

b. Persepsi Harga

Dalam arti sempit, harga (price) adalah jumlah yang ditagihkan atas suatu produk baik barang maupun jasa. Lebih luas lagi, harga adalah jumlah semua nilai yang diberikan oleh pelanggan untuk mendapatkan keuntungan dari memiliki atau menggunakan suatu produk baik barang maupun jasa (Kotler, 2008).

c. Indikator harga.

Adapun indikator harga menurut Rystamat dan Andjarwati (2014) yaitu:

1) Keterjangkauan harga.

2) Kesesuaian harga dengan kualitas.

3) Daya saing harga.

d. Lokasi

Menurut Kotler (2008) "Salah satu kunci menuju sukses adalah lokasi, lokasi dimulai dengan memilih komunitas". Keputusan ini sangat bergantung pada potensi pertumbuhan ekonomis dan stabilitas, persaingan, iklim politik, dan sebagainya.

e. Indikator- indikator lokasi.

Adapun indikator- indikator lokasi antara lain (Fure, 2013)

1) Ketersediaan lahan parkir

2) Memiliki tempat yang cukup luas

3) Akses transportasi yang mudah

4) Lokasi yang strategis

f. Word of Mouth

Kotler \& Keller (2007) mengemukakan bahwa word of mouth Communication (WOM) atau komunikasi dari mulut ke mulut merupakan proses komunikasi yang berupa 
pemberian rekomendasi baik secara individu maupun kelompok terhadap suatu produk atau jasa yang bertujuan untuk memberikan informasi secara personal. Komunikasi dari mulut ke mulut merupakan salah satu saluran komunikasi yang sering digunakan oleh perusahaan yang memproduksi baik barang maupun jasa karena komunikasi dan mulut ke mulut (word of mouth) dinilai sangat efektif dalam memperlancar proses pemasaran dan mampu memberikan keuntungan kepada perusahaan. Menurut Kotler \& Keller (2007).

g. Elemen-elemen Word of Mouth.

Menurut (Kotler \& Keller, 2007) menyebutkan bahwa ada 5 elemen-elemen (Five Ts) yang dibutuhkan untuk word of mouth agar dapat menyebar yaitu:

1) Talkers yaitu yang pertama dalam elemen ini adalah kita harus tahu siapa pembicara dalam hal ini pembicara adalah konsumen kita yang telah mengkonsumsi produk atau jasa yang telah kita berikan, terkadang orang lain cenderung dalam memilih atau memutuskan suatu produk tergantung kepada konsumen yang telah berpengalaman menggunakan produk atau jasa tersebut atau biasa disebut dengan referral pihak yang merekomendasikan suatu produk atau jasa.

2) Topics yaitu adanya suatu word of mouth karena tercipta suatu pesan atau perihal yang membuat mereka berbicara mengenai produk atau jasa, seperti halnya pelayanan yang diberikan, karena produk kita mempunyai keunggulan tersendiri, tentang perusahaan kita,lokasi yang strategis.

3) Tools yaitu setelah kita mengetahui pesan atau perihal yang membuat mereka berbicara mengenai produk atau jasa tersebut dibutuhkan suatu alat Universitas Sumatera Utara untuk membantu agar pesan tersebut dapat berjalan, seperti website game yang diciptakan untuk orang-orang bermain, contoh produk gratis, postcards, brosur, spanduk, melalui iklan diradio apa saja alat yang bisa membuat orang mudah membicarakan atau menularkan produk anda kepada temannya.

4) Taking Part atau partisipasi perusahaan yaitu suatu partisipasi perusahaan seperti halnya dalam menanggapi respon pertanyaan-pertanyaan mengenai produk atau jasa tersebut dari para calon konsumen dengan menjelaskan secara lebih jelas dan terperinci mengenai produk atau jasa tersebut, melakukan follow up ke calon konsumen sehingga mereka melakukan suatu proses pengambilan keputusan.

5) Tracking atau pengawasan akan hasil WOM marketing perusahaan setelah suatu alat tersebut berguna dalam proses word of mouth dan perusahaan pun cepat tanggap 
dalam merespon calon konsumen, perlu pula pengawasan akan word of mouth yang telah ada tersebut yaitu dengan melihat hasil seperti dalam kotak saran sehingga terdapat informasi banyaknya word of mouth positif atau word of mouth negatif dari para konsumen.

\subsection{Model Hipotesis}

Model hipotesis yang digunakan dalam penelitian ini dapat dilihat pada Gambar berikut:

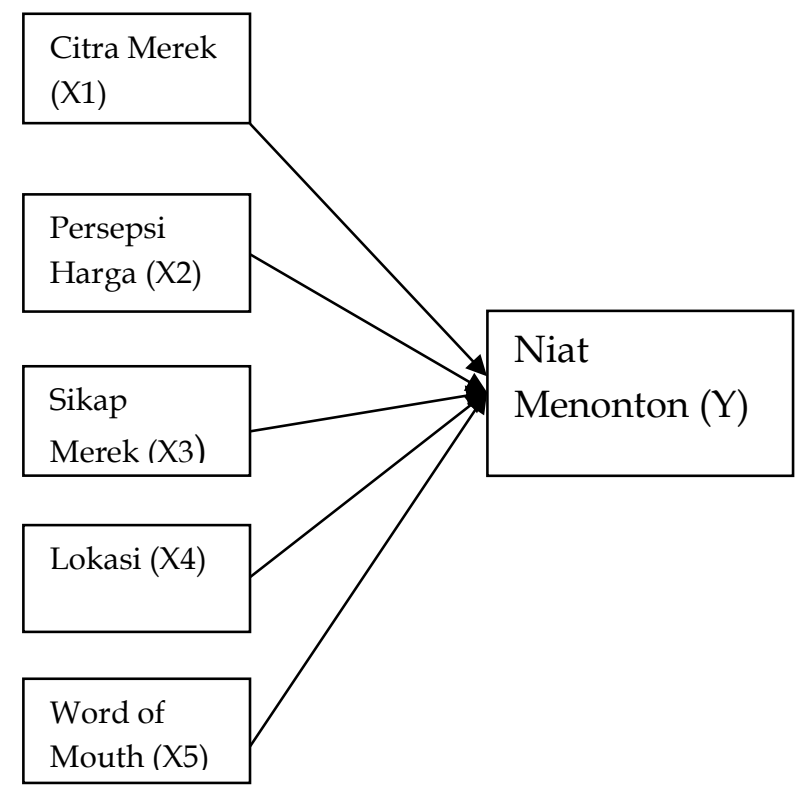

Gambar3: Kerangka konseptual Penelitian.

Hipotesis yang akan diuji dalam penelitian ini adalah:

H1 : Diduga citra merek memiliki pengaruh yang signifikan positif terhadap niat menonton di Cinema XXI.

H2 : Diduga persepsi harga memiliki pengaruh yang signifikan positif terhadap niat menonton di Cinema XXI.

H3 : Diduga sikap merek memiliki pengaruh yang signifikan positif terhadap niat menonton di Cinema XXI.

H4 : Diduga lokasi memiliki pengaruh yang signifikan positif terhadap niat menonton di Cinema XXI. 
H5 : Diduga WOM memiliki pengaruh yang signifikan positif terhadap niat menonton di Cinema XXI

\section{METODE PENELITIAN}

Eksplanatory research merupakan jenis penelitian yang dipilih oleh peneliti dalam penelitian ini dengan pendekatan kuantitatif. Pada penelitian ini peneliti memilih pengunjung yang pertama kali menonton di Cinema XXI Kota Padang lokasi penelitian. Variabel penelitian berupa variabel Citra Merek, Persepsi Harga, Sikap Merek, Lokasi, dan Word of Mouth.208 orang responden dipilih dalam penelitian ini untuk dijadikan sampel penelitian. Metode pengambilan sampel menggunakan teknik purposive sampling. Metode pengumpulan data menggunakan kuesioner. Dan jenis analisis data yang digunakan adalah metode Structural Equation Model (SEM)

\subsection{Variabel penelitian}

Dalam penelitian ini, variabel-variabel yang dimaksud adalah:

a. Citra Merek : keuntungan dari asosiasi mere, kekuatan dari asosiasi merek, keunikan dari asosiasi merek

b. Persepsi harga : keseuaian harga, harga yang ditawarkan,

c. Sikap Merek : ketertarikan, kesenangan, kepuasan,

d. Lokasi : ketersediaan lahan parkir, tempat yang cukup luas, akses yang mudah

e. Word of Mouth : menceritakan hal- hal yang positif, merekomendasikan kepada orang- orang, adanya dorongan

f. Niat menonton : bersungguh- sungguh, plihan yang terbaik

\section{HASIL DAN PEMBAHASAN}

Hasil analisis deskriptif menunjukkan bahwa

a. Berdasarkan hasil penyebaran kuesioner sebanyak 208 didapatkan responden berjenis kelamin perempuan sebanyak 150 (72\%) dan yang berjenis kelamin lakilaki sebanyak $58(28 \%)$. 
b. Responden dalam penelitian ini adalah yang rata-rata umurnya $<20$ tahun dan tidak lebih dari 50 tahun, responden mayoritas $<20$ tahun sebanyak $38(18 \%)$ responden $>50$ tahun sebanyak $4(2 \%)$.

c. Responden dalam penelitian ini adalah yang memiliki pendapatan terkecil Rp. 500.000 sebanyak 25 (12\%) dan penghasilan terbesar sebanyak $10(5 \%)$

\subsection{Pengujian Model.}

Penelitian ini menggunakan prosedur standar SmartPls untuk menganalisis data. Pls dikembangkan pertama kali oleh Wold sebagai metode umum untuk mengestimasi path model yang menggunakan konstruk laten dengan multiple indikator. Penganalisaan ini menggunakan dua langkah. Langkah pertama, model pengukuran menguji validitas dan realibiltas. Pada langkah kedua, model dioperasikan lagi untuk menguji hipotesis.

Langkah pertama, data ini di input ke Microsoft excel kemudian disimpan dengan ekstensi csv. Data- data ini tidak boleh ada yang kosong. Selanjutnya data diolah dengan SmartPLS 2.0 M3.

\subsection{Uji Validitas.}

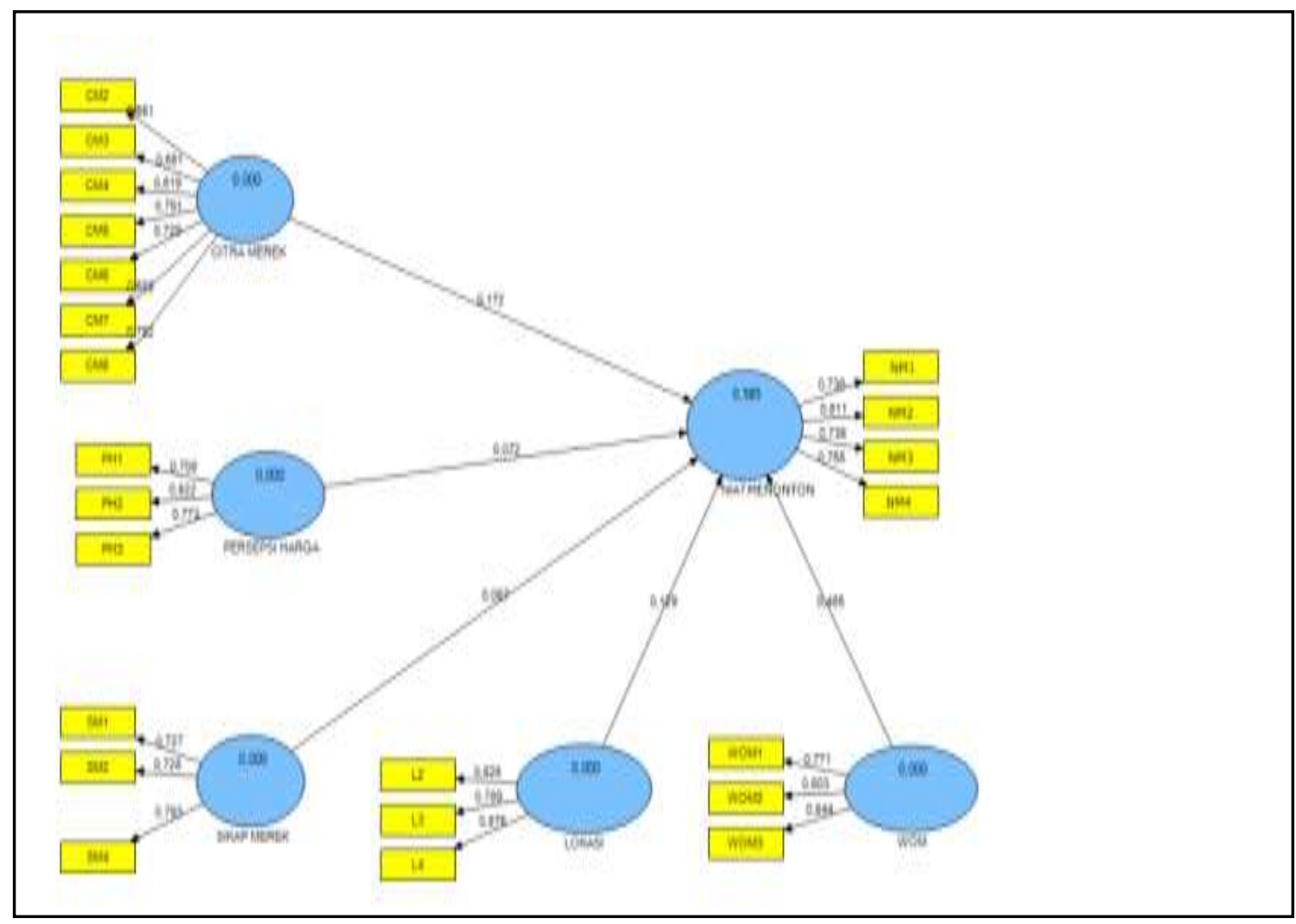

Gambar 4: uji validitas. 
Tabel 2

Cross Loadings

\begin{tabular}{ccccccc}
\hline & CITRA & LOKASI & NIAT & PERSEPSI & SIKAP & WOM \\
& MEREK & & MENONTON & HARGA & MEREK & \\
\hline CM2 & 0,651461 & 0,151598 & 0,394543 & 0,384485 & 0,242337 & 0,285372 \\
\hline CM3 & 0,680962 & 0,230811 & 0,432978 & 0,387526 & 0,306931 & 0,317782 \\
\hline CM4 & 0,618727 & 0,228454 & 0,325907 & 0,304181 & 0,22183 & 0,327828 \\
\hline CM5 & 0,791074 & 0,388271 & 0,411987 & 0,502108 & 0,371487 & 0,407017 \\
\hline CM6 & 0,728653 & 0,429692 & 0,366449 & 0,492630 & 0,409451 & 0,438841 \\
\hline CM7 & 0,688283 & 0,267225 & 0,297074 & 0,427185 & 0,262867 & 0,303338 \\
\hline CM8 & 0,792221 & 0,405351 & 0,453270 & 0,452856 & 0,336033 & 0,452247 \\
\hline L2 & 0,311000 & 0,825743 & 0,376881 & 0,308963 & 0,175114 & 0,41837 \\
\hline L3 & 0,350151 & 0,788944 & 0,358178 & 0,343524 & 0,160532 & 0,485791 \\
\hline L4 & 0,390872 & 0,875095 & 0,606410 & 0,359907 & 0,339394 & 0,663058 \\
\hline NM1 & 0,366638 & 0,393654 & 0,735939 & 0,400968 & 0,418399 & 0,565566 \\
\hline NM2 & 0,378360 & 0,440691 & 0,811243 & 0,379689 & 0,378629 & 0,635728 \\
\hline NM3 & 0,410155 & 0,442044 & 0,736261 & 0,348113 & 0,226631 & 0,437798 \\
\hline NM4 & 0,513546 & 0,452280 & 0,755402 & 0,403763 & 0,307186 & 0,547907 \\
\hline PH1 & 0,430141 & 0,238241 & 0,313216 & 0,708112 & 0,288372 & 0,332856 \\
\hline PH2 & 0,470164 & 0,335554 & 0,422700 & 0,822180 & 0,431552 & 0,473987 \\
\hline PH3 & 0,474614 & 0,351474 & 0,415963 & 0,773068 & 0,339897 & 0,358079 \\
\hline SM1 & 0,258941 & 0,113862 & 0,281809 & 0,364068 & 0,726548 & 0,32667 \\
\hline SM2 & 0,330311 & 0,203404 & 0,289589 & 0,363710 & 0,727835 & 0,340146 \\
\hline SM4 & 0,378511 & 0,308543 & 0,402924 & 0,332138 & 0,793393 & 0,391867 \\
\hline WOM1 & 0,358719 & 0,615161 & 0,519127 & 0,460392 & 0,400602 & 0,770787 \\
\hline WOM2 & 0,297422 & 0,417473 & 0,334552 & 0,152496 & 0,261579 & 0,602508 \\
\hline WOM3 & 0,466762 & 0,454734 & 0,692057 & 0,453166 & 0,385071 & 0,843829 \\
\hline Sum & & & & \\
\hline
\end{tabular}

Sumber: Hasil output Smartpls (2017).

Cross Loadings berguna untuk menilai apakah konstruk memiliki discriminat validity yang memadai, yaitu dengan cara membandingkan korelasi indikator suatu konstruk tersebut dengan konstruk lainnya. Jika korelasi indikator konstruk memiliki nilai lebih tinggi dibandingkan dengan korelasi indikator tersebut terhadap konstruk lain, maka dikatakan konstruk memiliki diskriminan validitas yang tinggi. 


\subsection{Uji Reliabilitas.}

Uji reliabilitas dilakukan dengan melihat nilai composite reliability dari blok indikator yang mengukur konstruk. Hasil composite reliability akan menunjukkan nilai yang memuaskan jika di atas 0,7 . Berikut adalah composite reliability pada output.

Tabel 3

Hasil Output Smartpls

\begin{tabular}{cc}
\hline & Composite Reliability \\
\hline CITRA MEREK & 0,875979 \\
\hline LOKASI & 0,869556 \\
\hline NIAT MENONTON & 0,845491 \\
\hline PERSEPSI HARGA & 0,812422 \\
\hline SIKAP MEREK & 0,793743 \\
\hline WOM & 0,786948
\end{tabular}

Sumber: Hasil output Smartpls (2017)

\subsection{Uji Hipotesis.}

Tabel 4

Uji Hipotesis

\begin{tabular}{|c|c|}
\hline & T Statistic \\
\hline Citra Merek $\rightarrow$ & 1,714002 Significant \\
\hline \multicolumn{2}{|l|}{ Niat menonton } \\
\hline Lokasi $\rightarrow$ Niat & 1,408803 insignificant \\
\hline \multicolumn{2}{|l|}{ Menonton } \\
\hline Persepsi harga & 0,780588 insignificant \\
\hline \multicolumn{2}{|l|}{$\rightarrow$ Niat } \\
\hline \multicolumn{2}{|l|}{ Menonton } \\
\hline Sikap Merek $\rightarrow$ & 2,179874 significant \\
\hline \multicolumn{2}{|l|}{ Niat Menonton } \\
\hline Wom $\rightarrow$ Niat & 4,146794 significant \\
\hline Menonton & \\
\hline
\end{tabular}

Sumber: Hasil output Smartpls (2017)

Uji hubungan antar konstruk menunjukkan bahwa Citra Merek (1,714002) Sikap Merek $(2,179874)$ WOM $(4,146794)$ berpengaruh significant terhadap niat menonton dimana dengan T hitung lebih kecil dari T tabel (T hitung $<$ T tabel 1,66). Sedangkan konstruk, Lokasi, Persepsi 
harga, dan tidak berpengaruh significant terhadap niat menonton. Sedangkan konstruk Lokasi $(1,408803)$ dan Persepsi Harga $(0,780588)$ hubungan yang tidak berpengaruh significant terhadap Niat Menonton dengan T hitung lebih kecil dari T tabel 1,66023 (T hitung < T tabel $1,66023)$.

\section{PEMBAHASAN HASIL PENELITIAN}

\subsection{Pengaruh citra merek terhadap niat menonton.}

Berdasarkan uji hipotesis dalam penelitian ini ditemukan bahwa citra merek (XI) berpengaruh signifikan terhadap niat menonton pengunjung di Cinema XXI . Hipotesis 1 diterima karena nilai $\mathrm{T}$ hitung 1,714002> T tabel yaitu 1,66. Sehingga dapat disimpulkan bahwa hipotesis 1 diterima.

\subsection{Pengaruh persepsi harga terhadap niat menonton}

Berdasarkan uji hipotesis dalam penelitian ini ditemukan bahwa persepsi harga (X2) tidak berpengaruh signifikan terhadap niat menonton pengunjung di Cinema XXI . Hipotesis 2 ditolak karena nilai T hitung 0,780588 < T tabel yaitu $<1$.66.Sehingga dapat disimpulkan bahwa hipotesis 2 ditolak.

\subsection{Pengaruh sikap merek terhadap niat menonton.}

Berdasarkan uji hipotesis dalam penelitian ini ditemukan bahwa sikap merek (X3) berpengaruh signifikan terhadap niat menonton pengunjung di Cinema XXI . Hipotesis 3 diterima karena nilai T hitung 2,179874, $>$ T tabel yaitu $<1.66$. Sehingga dapat disimpulkan bahwa hipotesis 3 diterima.

\subsection{Pengaruh lokasi terhadap niat menonton.}

Berdasarkan uji hipotesis dalam penelitian ini ditemukan bahwa Lokasi (X4) tidak berpengaruh signifikan terhadap niat menonton pengunjung di Cinema XXI . Hipotesis 4 ditolak karena nilai $\mathrm{t}$ hitung 1,408803 < t tabel yaitu $<1.66$..Sehingga dapat disimpulkan bahwa hipotesis 4 ditolak.

\subsection{Pengaruh Word of Mouth terhadap niat menonton.}

Berdasarkan uji hipotesis dalam penelitian ini ditemukan bahwa WOM (X5) berpengaruh signifikan terhadap niat menonton di Cinema XXI . Hipotesis 5 diterima karena nilai $\mathrm{t}$ hitung 4,146794 < t tabel yaitu $<1$.66. Sehingga dapat disimpulkan bahwa hipotesis 5 diterima. 


\section{KESIMPULAN}

Penelitian ini menggunakan 5 variabel yaitu Citra merek, Persepsi harga, Sikap merek, Lokasi, dan Word of Mouth terhadap Niat beli. Penelitian ini dilakukan dengan menyebarkan kuesioner kepada 208 responden. Data pada penelitian ini diolah dengan menggunakan Microsoft Excel 2007 dan SmartPLS 2.0. M3.

Berdasarkan hasil analisis dan pembahasan pada bab sebelumnya maka dapat diambil kesimpulan sebagai berikut:

a. Citra merek memberikan pengaruh yang signifikan terhadap niat menonton di Cinema XXI.

b. Persepsi harga tidak memberikan pengaruh yang signifikan terhadap niat menonton di Cinema XXI.

c. Sikap merek memberikan pengaruh yang signifikan terhadap niat menonton di Cinema XXI.

d. Lokasi tidak memberikan pengaruh yang signifikan terhadap niat menonton Cinema XXI.

e. Word of Mouth memberikan pengaruh yang signifikan terhadap niat menonton di Cinema XXI.

\section{DAFTAR PUSTAKA}

Ajzen, I. (2015). Consumer Attitudes and Behavior: “The Theory of Planned Behavior Applied to Food Consumption Decisions". Rivista di Economia Agraria, Anno LXX, n. 2, 2015: 121138. DOI: 10.13128/REA-18003. ISSN (print): 0035-6190. ISSN (online): 2281-1559.

Augusty, Ferdinand. (2009). "Pengembangan Niat Beli Merek Ekstensi". Semarang: Badan Penerbit Universitas Diponegoro,

Bilson, Simamora. (2011). "Memenangkan Pasar dengan Pemasaran Efektif dan Profitabel". Jakarta: PT. Gramedia Pustaka Utama.

Chinomona, Richard. (2013). "The Impact of Product Quality on Perceived Value, Trust and Students Intention to Purchase Electronic Gadgets". Mediteranean Journal of Social Sciences. Vol. 4 No. 14.

Fandy, Tjiptono. (2005). "Pemasaran Jasa". Malang. Bayumedia Publishing. Freddy Rangkuti. (2009). “Strategi Promosi yang Kreatif”. Jakarta : Gramedia Pustaka Utama. 
Fure. (2013). “Lokasi, Keberagaman Porduk, Harga, dan Kualitas Pelayanan, Pengaruhnya Terhadap

Niat Beli Pada Pasar Tradisional Bersahati Calaca".Jurnal. EMBA. Vol.1 No.3. Sepetmber.2013.

Ghozali. (2008). “Structural Equation Modeling Metode Alternative Dengan Partial Least Square $(P L S)^{\prime \prime}$, Badan Penerbit Universitas Diponegoro, Semarang.

Hansen \& Mowen. (2006). “Manajemen Pemasaran”. Jilid 1. Edisi 7. Salemba Empat. Jakarta. Haryoko. (2005). "Pengaruh Harga, Desain, dan Fitur Produk terhadap Niat beli Produk Handphone (Studi Kasus pada Mahasiswa Reguler dan Diploma III Fakultas Ilmu Sosial dan Ilmu Politik Universitas Diponegoro". Skripsi. Universitas Diponegoro.Semarang.

Hatane Samuel, Adi Suryanata Lianto. (2014). “Analisis WOM, Brand Image, Brand Trust, dan Niat Beli Produk Smartphone". Fakultas Ekonomi. Universitas Kristen Putra. Surabaya. Jr Joseph, dkk. (2013). "A Primer on Partial Least Square Structural Equation Modelling" (PLSSEM). Los Angeles. London. New Delhi.

Kartajaya. (2006). “Marketing Mix”. ElemenMarketing. Bandung. PT. Mizan Pustaka.

Khan Saba, dkk. (2015). “Impact WOM on Consumer Purchase Intention”.Pakistan.

Kotler, Philip. (2008). “Manajemen Pemasaran". Jilid 1, Jakarta, PT. Indeks Kelompok Gramedia.

Kotler, Philip and Keller.(2009). “Manajemen Pemasaran". Edisi Tiga Belas. Jilid 1.J akarta: Erlangga.

Kotler, Philip and Gary Amstrong. (2012). "Prinsip- Prinsip Pemasaran". Edisi 13.Jilid 1. Jakarta Erlangga.

Leo Agung Manggala, Yogatama. (2013). “Analisis Pengaruh Attitude, Subjective Norm, dan Perceived Behavior Control terhadap Intensi Penggunaan Helm Saat Mengendarai Motor pada Remaja dan Dewasa Muda di Jakarta Selatan". Prosiding PESAT 5.

Linan, and Chen. (2006). "Testing the Entrepreneurial Intention Model on a Two Country Sample". Department d' Economia de l'Empresa.

NST Rizky \& Yasin Hanifa (2014). “Pengaruh Promosi dan Harga Terhadap Niat Beli” Universitas Sumatera Utara. STIE Nusa Bangsa. Medan.

Oosthuizen. (2015). “The Relationship Between Perceived Price and Consumers Purchase Intentions of Private Label Wine Brands". Africa journal of Hospitally. Tourism and leisure. Vol. 4 (2).

Schiffman \& Kanuk. (2004). "Perilaku Konsumen”. Edisi ketujuh. Jakarta : Prentice Hall. . (2007). “Prilaku Konsumen”. Edisi kedua. Jakarta: PT. Indeks Gramedia.

Sekaran, Uma. (2006). Metode Riset Untuk Bisnis.Edisi ke-4. Salemba Empat. Jakarta. 
(2015). "Research Methods for business". Edisi I and 2. Jakarta: Salemba Empat.

Shwu-ing Wu. (2016). "The influence of Brand Attitude and Consumer Perception on Purchase Intention Towards Extended Product". Department of Business Adminsitration. National Chin-Yi University of Technologi. Taiping - Taiwan.

Solesvik. (2012). "Student Intentions to Become Self Emlpoyed: The Ukrainian Context". Journal of Small Business and Enterprise Development. Vol. 19. No. 3

Sugiarto, Budi Utomo dan Subagio, Hartono (2014). “Analisa Pengaruh Produk, Kualitas Pelayanan, Harga, dan Store Atmosphere Terhadap Niat Beli di Dream Of Khayangan Art Resto Surabaya". Jurnal Manajemen Pemasaran. Vol. 2. No. 1.

Sugiyono.(2009). Metode Penelitian Bisnis. Bandung: Alfa Beta.

Sunyoto, D. (2015). "Perilaku Konsumen dan Pemasaran". Yogyarta : Center of academic publishing service.

Susanti \& Adisaputra (2011) "Pengaruh Brand Image Speedy Telkom Terhadap Loyalitas Pelanggan di Kecamatan Bayumanik Semarang". Universitas Diponegoro. Semarang.

Sutisna. (2001). "Perilaku Konsumen dan Komunikasi Pemasaran". PT. Remaja Rosdakarya, Bandung.

Tahapary, Grace. (2015). “Faktor- Faktor yang Mempengaruhi Keputusan Pembelian pada Bioskop 21 Ambon Plaza" .Fakultas Ekonomi.Universitas Pattimura.

Tsordia \& Papadimitriou. (2015). “The Role of Theory of Planned Behaviour on Entrepreneurial Intention of Greek Business Students". International Journal of Synergy and Research. Vol. 4. No. 1. 2015.Page. 23-37. 